\title{
Um olhar sobre a francofilia \\ presencista: ecos de um amor não correspondido
}

Márcia Seabra Neves

Recebido em 22 mai 2012 - Aprovado em 24 set 2012

\section{Resumo}

Está sobejamente comprovado o fascínio que a cultura e literatura francesas desde sempre exerceram no imaginário português. Ora, os escritores que, em 1927, se reuniram em torno da revista presença (1927-1940), não escaparam a esta sedução francófila, aliás por eles expressamente assumida. Com efeito, ao percorrermos as páginas da revista coimbrã deparamo-nos com uma constante referência à língua e cultura francesas. Convém, contudo, sublinhar que a francofilia presencista se reveste de traços singularizadores e, de certo modo, seletivos, uma vez que do amplo reportório literário e cultural francês, foi a Nouvelle Revue Française, tutelada pelo magistério crítico e doutrinário de André Gide, que a geração da presença elegeu como paradigma estético-literário. No entanto, o fascínio e admiração do grupo de Régio pela bande à Gide não conhece reciprocidade e o diálogo entre as duas revistas/gerações manter-se-á unilateral, apesar das várias tentativas de aproximação por parte dos presencistas.

Palavras-chave: Nouvelle Revue Française, presença; francofilia; mediação; diálogo luso-francês. 
O fascínio que a cultura e literatura francesas exerceram, até recentemente, na forma mentis e na fisionomia cultural nacionais é um facto incontestado, que se reflectiu, de forma evidente, na literatura portuguesa, desde os seus primórdios ${ }^{1}$.

Comparativamente, são escassos os sinais de projecção da cultura portuguesa no estrangeiro. Com efeito, ocupando uma situação ex-cêntrica em termos geoestratégicos, que impediu a sua afirmação além-fronteiras, Portugal permaneceu, durante muito tempo, confinado à margem da Europa. Pierre Hourcade, indefectível admirador da cultura portuguesa e infatigável mentor da sua divulgação em França, observou, de modo pertinente que:

O primeiro paradoxo da literatura portuguesa é a sua própria existência, ligada à duma língua e duma nação que conquistaram desde muito cedo a sua autonomia mas que, relegadas no extremo ocidental da Europa, ocultadas pela poderosa dimensão da Espanha e da cultura castelhana, corriam o forte risco de serem sufocadas ou de morrerem de inanição. (HOURCADE, 1978, p. 13)

Com efeito, as relações culturais e literárias entre Portugal e a metrópole francesa sempre se processaram mais em termos de hegemonia francesa do que em termos de paridade recíproca. Este carácter assimétrico e unilateral do diálogo luso-francês é sublinhado, nas páginas da presença, pela mão de Régio, o seu grande mentor:

Portugal é um país que os outros países ignoram; e que pouco oferece (diga-se toda a verdade) capaz de reter a sua atenção. (...) Mas é triste constatarmos que nem aos maiores dos nossos cabe a honra que tantas vezes cabe a escritores menores doutros países. (...) É injusto que um Camilo, um Gil Vicente, um Eça, (...) etc, etc, etc, (...) não figurem em qualquer dessas edições modernas, compulsáveis, vulgarizadoras, ou sistemáticas, eruditas, graves, com que, por exemplo, a França adopta tantos escritores estrangeiros, modernos ou não ... E sobretudo, é triste que em nenhum desses milhares de estudos críticos publicados hoje, - e em que tanto nome se evoca, se aproxima, se desfibra - apareça um nome português familiar

${ }^{1}$ Este estudo retoma e sintetiza algumas conclusões decorrentes da investigação realizada no âmbito da tese de doutoramento da autora, subordinada ao tema da francofilia na literatura portuguesa, focando em particular a influência da Nouvelle Revue Française na revista presença. Intitulada Da francofilia no imaginário presencista: da NRF à presença, a tese foi apresentada à Universidade de Aveiro, em 2010, e encontra-se presentemente em curso de publicação pela Fundação Calouste Gulbenkian. ao crítico. (RÉGIO, 1931, p. 12)

Embora conscientes desta realidade, a verdade é que os escritores que, em 1927, se reuniram em torno da pequena folha de arte e crítica, a que deram o nome de presença, não ficaram imunes a esta generalizada sedução francófila. São, aliás, eles próprios que assumem, declaradamente, estreitas afinidades espirituais com a pátria de Baudelaire.

Uma das manifestações mais evidentes desta proclividade é constituída pela famosa polémica entre a presença e La Gaceta Literária (1927-1932) que se revelará fundamental para a compreensão da natureza das relações dos presencistas com a cultura francesa. Nascidas no mesmo ano, a presença e La Gaceta Literária sempre mantiveram uma relação de mútua cordialidade, até a revista 
madrilena ter criado nas suas páginas uma Gaceta Portuguesa, a par das gazetas catalã e americana. Embora reconhecendo que essa iniciativa pudesse representar - caso fosse bem dirigida - um inestimável contributo para a divulgação da literatura portuguesa contemporânea além-fronteiras, os presencistas contestaram o formato da publicação da gazeta portuguesa, argumentando:

Uma página portuguesa, ainda que escrita em português, abraçada num círculo de páginas duma região e de países que os próprios dirigentes de La Gaceta Literária, não há muito tempo, afirmavam subordinados ao meridiano intelectual de Madrid - mostrar-nos-há ao resto da Europa e à América subordinados a esse mesmo meridiano. O que não é verdade! (REDAÇÃO, 1929, p. 11)

Por outro lado, os presencistas acusavam a Gaceta Literária de transcrever páginas da presença sem mencionar a sua proveniência. Na secção Comentário do $n^{\circ} 24$ da revista, denunciam este facto, reproduzindo os decretos-lei referentes aos direitos de propriedade literária e artística.

O ponto culminante da polêmica ocorre quando, num artigo publicado no número de Janeiro de 1930 da referida revista, Gimenez Caballero "tão levianamente acusa Portugal de não ter descoberto senão a França no políticoliterário, e tão gratuitamente dá ainda a França como guia fundamental, obsesionante da presença" (ibid., p. 14). Esse artigo exasperou os presencistas, que logo replicaram com um extenso e ácido comentário, atribuindo tais alegações a putativas ambições nacionalistas de Caballero e de outros espanhóis, que sonhavam com um "império cultural cuja capital fosse Madrid re-espanholizado, e ao qual Portugal pertenceria" (ibid.). O comentário prossegue, dando ênfase ao espírito independente e cosmopolita da presença que, não temendo as influências estrangeiras, acolhe nas suas páginas as mais diversas épocas, escolas ou nacionalidades, e não exclusivamente a francesa, embora se sublinhe a particular congenialidade dos presencistas com alguns franceses contemporâneos:

Sendo uma revista literária, - é sobretudo à literatura que a presença tem consagrado a sua mais contínua actividade. Mas a Arte interessa-lhe sob qualquer das suas manifestações disso tem dado provas. $\mathrm{E}$ tal interesse não conhece limites de raças, nem de nacionalidade, nem de épocas, nem de escolas, nem seja do que fôr. Somos principalmente artistas, amigo Caballero; e isto de em verdade se ser artista, - ainda é uma superioridade. Ora bem!: Se neste universalismo nos encontramos (eis o termo justo: encontrar) com alguns dos grandes franceses contemporâneos - Por exemplo: com André Gide - não pensamos que nos deva desgostar o facto de termos de comum com André Gide essa largueza de curiosidade. (...) De resto, e insistindo, não receamos tornarmo-nos franceses pelo facto de admirarmos vários franceses. (...) A jovem revista presença já não receia tais coisas: Para ela, a capacidade de 
admirar o admirável - é uma superioridade e uma afirmação de individualidade. (ibid.)

Esta polêmica será retomada por Pierre Hourcade no seu artigo intitulado "Defesa e ilustração da poesia portuguesa viva" (HOURCADE, 1931, p. 13-15), traduzido por Gaspar Simões e publicado na presença. O texto é precedido de uma nota introdutória, em que se sublinha a importância de tal "depoimento sobre a literatura portuguesa chamada modernista" (ibid., p. 13), não só pelo fato de facultar "uma visão de conjunto das tendências e do significado europeu dessa literatura" (ibid.), como também, e sobretudo, por constituir um "juízo formulado por um francês sobre as pretensas influências francesas nas novas correntes artísticas portuguesas" (ibid.). Com um currículo essencialmente dedicado à literatura portuguesa moderna, Pierre Hourcade é apresentado como sendo "hoje o único francês que pode dizer alguma coisa sobre a nossa literatura" (ibid.):

Enfim há alguém, em França, que nos olha e nos compreende com olhos vivos, olhos de artista e de crítico - que não com olhos de erudito. Infelizmente temos sido sempre vistos através dos "documentos". Honra seja feita a Pierre Hourcade. (ibid.)

Este artigo merece especial atenção, na medida em que constitui um documento amplamente elucidativo do diálogo cultural e literário entre Portugal e França, incidindo particularmente nas relações dos escritores portugueses modernos com a literatura francesa. Em ressalva preambular, Hourcade começa por estabelecer inequivocamente que "a poesia portuguesa nunca foi uma variante da espanhola, que a Ibéria é um mito e que La Gaceta Literária, por melhor boa vontade que tenha, nunca foi e nunca será o órgão do modernismo lusitano" (ibid.). Eis então equacionadas as questões cruciais que o crítico se propõe debater: o carácter específico e idiossincrático da cultura lusitana e a famigerada polémica entre a presença e La Gaceta Literária que detonou uma sintomática querela em torno das influências da França sobre a literatura moderna portuguesa.

Relativamente ao primeiro ponto, Hourcade insiste na distinção entre os dois países e respectivas culturas, negando resolutamente a unidade Ibérica, responsável pela subalternização de Portugal pela proeminente Espanha que "com o seu maciço espinhaço, esconde ao continente toda uma cultura viva, todo um presente saboroso, que sobreviveu às piores decadências económicas e sociais" (ibid.). Neste sentido, o crítico censura com acrimônia polemizante todos aqueles que confundiam Espanha e Portugal, afirmando que só "Valery Larbaud (ainda, em parte escravo, das recepções oficiais e de Ramon Gomez de La Serna, filho duma outra terra), só o autor de Jaune Bleu Blanc entreviu a vida intelectual de entre Tejo e Douro, no extremo ocidente do mundo europeu" (ibid.). Transita, então, para uma descrição evo- 
cativa do "clima moral particularíssimo" (ibid.) e da "atmosfera poética" (ibid.) que servem de palco à nova geração de escritores modernistas portugueses, revelando uma apurada inteligência da alma poética lusitana e desvendando os contornos da sua afectuosa lusofilia:

Portugal: extremidade do cabo europeu desenhado por Valéry, onde se encontram e compõem, numa abundância de antíteses, a magia meridional e o sopro das grandes planícies marinhas. Terra de preguiçosos e de pacientes, descobridores de mundos, de retóricos e de audazes, de luz e de pessimismo, de ardor e de total abandono. Trovadores provençais semearam-lhe, no tempo dos primeiros soberanos burguinhões, os germens duma paixão que os séculos tornaram em febre - o lirismo. Com as desgraças nacionais, as doenças coloniais, os desastres económicos, a queda na sombra adensada pela rapacidade ou a ingratidão das grandes potências vizinhas, essa alegre voz ensurdeceu, enlanguesceu. No lirismo enxertou-se a "Saudade", palavra intraduzível, inimitável movimento da alma ansiosa, desamparada, abandonada de toda a esperança. (...) Desde então o país diminuiu, a Europa desconheceu-o ou explorou-o, a recordação tornou-se obsessão, o desejo tentação insaciável. Donde a incurável melancolia que com o tempo se insinuou na sua literatura, não sem revoltas e regressos duma furiosa ironia, mas, contudo, conservando-se essencial até ao ponto de se impor como uma máscara a todo o pensamento e a toda a acção que despontam. Saudade e ironia: os dois movimentos ligados um ao outro, alternando nas melhores páginas de todos os escritores e poetas portugueses dignos de tais nomes. (...) Eis aqui um país onde a tragédia da expressão lírica, do recurso às potências interiores, do conflito entre o verbo e a voz do sangue inerente a todo o lirismo, coincide exactamente com o próprio drama da história nacional e da existência quotidiana. Donde a importância predominante, quási esmagadora, assumida pela poesia na literatura deste povo. (ibid., p. 13-14)

Após esta efusiva contextualização, Hourcade procede a um rastreio da literatura portuguesa contemporânea, pretendendo apurar a natureza e a função das suas influências e dilucidar certos equívocos que se tinham instalado a esse propósito. É precisamente com esse intuito que Hourcade começa por se dirigir explicitamente a Ernesto Gimenez Caballero, o director de La Gaceta Literária, relembrando as motivações que estiveram na gênese da polêmica entre a revista madrilena e a coimbrã:

Num artigo publicado durante o último Inverno, o célebre crítico, depois de inserir na sua revista uma "página portuguesa" com o mesmo pretexto que uma página catalã e uma sul-americana, depois de ter, sob a rubrica "literatura espanhola", citado alguns bastante longos fragmentos da revista "presença", de Coimbra, lançava-se numa guerra aberta contra a influência da literatura francesa moderna sobre os novos escritores portugueses, protestava contra o seu carácter tirânico e exclusivo, 
afirmava a sua ineficácia e o perigo de esterilização e de cosmopolitismo sem grandeza nem verdade a que uma imitação demasiado fiel arriscava os seus discípulos imprudentes. Toda esta diatribe acabava com uma frase poética e retorcida, em que o Senhor Gimenez Caballero convidava os escravos da moda francesa a quebrarem as cadeias para se precipitarem nos braços maternalmente abertos da grande irmã ibérica, e, corolário inesperado, para se retemperarem ao mesmo tempo nas águas do pensamento germânico". (ibid., p. 14)

Enquanto francês e amigo sincero da presença, Hourcade não podia deixar de tomar posição na contenda, afirmando que não se verifica unidade de influências entre os escritores portugueses contemporâneos, consorciados precisamente na "vontade de liquidar os últimos destroços duma geração e duma cultura anteriores repleta de importações francesas muito ou pouco assimiladas, e de procurar as condições duma cultura verdadeiramente internacional fora de toda a familiaridade e de toda a ingenuidade" (ibid.). Hourcade acentua assim a inclinação cosmopolita da literatura portuguesa, que se concretizava essencialmente pela intermediação da França, uma vez que a língua francesa funcionava como sistema veicular de acesso às outras línguas e culturas europeias. Com efeito, era por interpostas traduções francesas que a elite intelectual portuguesa acedia às literaturas estrangeiras:

Se se folhearem as colecções das revistas novas ser-se há chocado de ver aparecer continuamente os grandes nomes da Europa dos trinta últimos anos (...) Apenas, como a língua francesa é a única verdadeiramente espalhada na elite intelectual portuguesa, é ela que serve de veículo a todas as outras culturas, sendo através das nossas traduções (salvo para as obras espanholas) que toda a Europa chega ao conhecimento da maior parte dos portugueses. E se o hábito lhes deu preferência na leitura da nossa língua a qualquer outra é deles, não de nós, que o Senhor Gimenez Caballero se deve queixar. Eu, pela minha parte, aconselhar-lhe hei que dirija a sua petição ao Ministro da Instrução Pública, em Lisboa, e a todas as grandes livrarias dessa capital. Pela nossa parte não teríamos um despeito nacionalista tão idiota ao ponto de nos sentirmos ofuscados. (ibid.)

No seu artigo, Hourcade apresenta uma lúcida e penetrante cartografia do modernismo português. Inclinada para "o conhecimento mais directo e a expressão mais sincera de si próprio" (ibid.), a nova geração modernista preconiza uma literatura autêntica e antiformalista, não abdicando da independência do espírito e das ideias. Assim, embora impregnada de um espírito cosmopolita e receptiva a todas as tendências e influências, a literatura modernista está longe de poder ser considerada ancilar de qualquer volátil moda ou escola literária. Numa sinopse certeira, o crítico apresenta uma expressiva descrição da literatura modernista portuguesa, recorrendo a um jogo discursivo de antíteses e paradoxos: 
Saborosa, na verdade, é esta literatura verdadeiramente "gratuita", em todos os sentidos possíveis desta palavra pretensiosa de que tanto se tem abusado. Alimentada de todas as influências internacionais, atenta a assimilar todas as obras-primas da arte viva, aberta a todos os sopros e acessível a todas as correntes, permanece, conforme a tradição, amorosa, melancólica, ansiosa, sarcástica e, acima de tudo, perdidamente fantasista. Foge à análise, desafia as comparações, salta por cima de todas as fronteiras, confunde os géneros, mistura o lirismo na metafísica e desencadeia a metafísica no lirismo, afirma-se em pleno orgulho e nega-se em pleno desânimo, calca a terra de que é inseparável e rasga a estrangeira de que é ávida, é idólatra e anarquista, pagã e mística, cabotina e humilhada, pessimista e sempre confiante no futuro, resume todas as contradições da raça e da época sem nunca as esgotar nem se esgotar. É pródiga em poetas, em ensaístas, em contistas fantásticos, em profetas entusiastas, em romancistas apaixonados e, no meio de toda esta explosão de loucura e de mocidade, conserva bom senso, domínio de si, e uma sabedoria sem rotina e sem preconceitos. (ibid.)

O estudo é rematado com uma enumeração dos principais escritores modernistas portugueses, desde os que vinham já de Orpheu - Fernando Pessoa, Sá-Carneiro, Almada Negreiros, António Botto, Afonso Duarte, Mário Saa - aos jovens da presença - Régio, Gaspar Simões, Branquinho da Fonseca, Casais Monteiro, Adolfo Rocha, Carlos Queirós, António de Navarro, Francisco Bugalho...

Em 1983, numa comunicação proferida na Fundação Calouste Gulbenkian e intitulada "presença da literatura francesa na presença da literatura portuguesa" (SIMÕES, 1984, p. 123-132), João Gaspar Simões declarava que a "lição da cultura da França, num dos seus aspectos mais importantes, no que toca à presença portuguesa, revestir-se-ia de características por assim dizer inéditas" (ibid., p. 124) e que a novidade desta presença se traduzia "num espectro cultural muito mais alargado do que o espectro cultural de qualquer outra anterior presença francesa nas letras portuguesas" (ibid.). O crítico sublinhava, deste modo, a peculiar abrangência da francofilia presencista, correlacionando a presença francesa na presença portuguesa com a "cultura instituída pelo movimento da Nouvelle Revue Française" (ibid., p. 123).

Assim, de todo o legado literário e cultural francês, os presencistas elegeram a NRF como paradigma estético e doutrinário. A revista coimbrã tornará óbvia, ao longo das suas páginas, uma programada sintonia com a arte e literatura francesas e, muito em particular, com la bande à Gide, em contacto com a qual os escritores da presença apuraram o seu espírito crítico, expandiram os seus conhecimentos e participaram, mesmo vicariamente, do que se passava além-fronteiras. Com efeito, se por um lado, a língua francesa, então considerada como uma "língua universal" (FIUMI, 1935, p. 7), se impunha como veículo idiomático de 
acesso às restantes literaturas, já que era pela intermediação das traduções francesas que os presencistas acediam às obras dos autores estrangeiros; por outro, os críticos da NRF sugeriam aos da presença o instrumentário crítico necessário para a apreensão e análise dessas obras. Não será, portanto, abusivo afirmar que a revista de Gide foi uma placa giratória entre a cultura portuguesa e as outras culturas, daí a admiração dos presencistas por essa notável publicação.

São, de fato, múltiplos os documentos que comprovam que os principais mentores da presença eram leitores assíduos da NRF. Uma dessas provas abonatórias é constituída pela vasta correspondência entre Régio e João Gaspar Simões, na qual, ao relatar uma visita a Adolfo Casais Monteiro, o autor dos Poemas de Deus e do Diabo anota a opulência da biblioteca daquela "avis rara (no Porto!) que possui todo o Gide, todo o Proust, e vários Valerys, Pirandellos, etc" (SIMÕES, 1977, p. 215). Quanto a Gaspar Simões, ele próprio confessa, ao historiar o nascimento da presen$c ̧ a$, que "todas as semanas, uma vez, pelo menos, desembarcava na Estação Nova com a [sua] Nouvelle Revue Française debaixo do braço (...) para sentar-[se] à mesa do café, no meio do cenáculo onde José Régio realmente pontificava" (ibid., p. 157). O crítico sublinha mesmo que, por essa altura, era ele "o único leitor assíduo da revista" (ibid.). Sabemos também que Simões era um fiel assinante da $N R F$, não só pelo fato de do seu espólio constar a coleção quase completa da revista, mas também pelo postal que recebera de Hirch, o diretor comercial das edições Gallimard, a confirmar a recepção da sua assinatura à NRF (HIRSCH, 1927), que será, aliás, uma das revistas recebidas regularmente pela presença, encontrando-se arrolada na lista de periódicos constantes da secção Correio da presença.

Outro testemunho desta presença tutelar da NRF é o artigo de Pierre Hourcade, intitulado "O ensaio e a crítica na presença" (HOURCADE, 1977, p. 20-28), no qual é destacada a orientação francófila dos presencistas, polarizada sobretudo na Nouvelle Revue Française, "cuja evolução acompanham mês após mês com tão vigilante atenção (quantos artigos da Nouvelle Revue Française citados e comentados logo no mês seguinte à sua publicação em França!)" (ibid., p. 24), e em alguns dos seus autores, com os quais eles mais se identificam, tais como Proust e Gide, passando também pela "posteridade poética de Baudelaire e de Rimbaud, até ao Surrealismo" (ibid.).

No entanto, a maior prova testemunhal da hegemonia da cultura francesa, e em particular da $N R F$, na presença encontra-se na própria revista e consiste no avultado número de autores franceses evocados ao longo das suas páginas. Com efeito, poucos são os ensaios, recensões críticas ou comentários de onde não conste uma menção a uma personalidade artística francesa. 
Um levantamento exaustivo dos autores franceses citados na presença permitiu-nos constatar que é, sem dúvida, no campo literário que os presencistas mais recorrem aos precedentes culturais franceses. No topo da lista dos autores mais citados, encontra-se Marcel Proust, o mestre do romance; segue-se André Gide, o modelo da crítica e, em terceiro lugar, vem Paul Valéry, quase poeta por antonomásia. Assim, "à tríade nacional de mestres ou de faróis (...), constituída por Pessoa, Sá-Carneiro, Almada" (MOURÃO-FERREIRA, 1984, p. 134-135), os presencistas acrescentaram a "tríade francesa Proust - Valéry - Gide" (ibid., p. 135).

Foi, pois, no panteão da NRF que a presença se inspirou para a conformação do seu cânone artístico, já que praticamente todos os autores franceses citados na revista de Régio pertenceram à $N R F$ de forma activa ou, indirectamente, na qualidade de objecto de atenção crítica. De todo o universo estético-literário francês, foi a NRF de orientação gideana que os presencistas elegeram como referência estética. Com efeito, em praticamente todos os seus escritos teórico-críticos, os escritores da presença recorrem aos textos seminais da NRF para validar os seus argumentos e para ilustrar ou substanciar as suas teses, amparando-se nas suas teorias e axiomas como estratégias demonstrativas.

Aos olhos dos presencistas, os autores da NRF representam verdadeiros paradigmas estético-literários. Proust e Gide são encarados como insuperáveis artistas do seu tempo, ambos independentes e livres, sendo o primeiro evocado como um caso modelar de originalidade criadora e um dos grandes mestres modernos. Apollinaire, Cocteau, Max Jacob, Salmon e Reverdy são considerados os grandes gênios franceses modernistas responsáveis pela renovação do romance, da poesia e do teatro. Claudel, Breton, Valéry, Supervielle, Mallarmé, Baudelaire, Fargue, Soupault, Debussy, Picasso ou Cézanne são outros notáveis cultores da arte moderna.

É, pois, a partir dos ideais estéticos divulgados pela NRF que os críticos da presença desenvolvem a sua leitura crítica dos escritores portugueses. Com efeito, são assíduas, ao longo das páginas da presença, as incursões comparatísticas de âmbito luso-francês: Proust e Os Maias, Pessanha e Verlaine, Flaubert e Fernando Pessoa, Octave Mirbeau e Raul Brandão, Leonardo Coimbra e Montaigne / Pascal, Almada e Rimbaud / Cocteau, Flaubert e Eça, António Nobre e Verlaine.

No fundo, aos homens da NRF, os críticos da presença deveram, sobretudo, "o fecundo auxílio de novas lentes de apreciação" (ibid., p. 134) e "o tal crítico instrumento de óptica" (ibid.) através do qual olharam, não só para a literatura francesa, como também para a de outras línguas e nacionalidades, nomeadamente a portuguesa. Assim, as inúmeras "referências a criadores e a críticos franceses em artigos que tratam ou de autores de outras línguas e nacionalidades (portugueses pela maior parte) ou de temas literários de carácter geral" (ibid., p. 133-134) não deixam dúvidas 
relativamente a "uma certa tutelar presença na presença, do que foi La Nouvelle Revue Française entre as duas guerras" (ibid., p. 134).

No entanto, a afetuosa admiração dos presencistas pela $N R F$ não conhece reciprocidade. Se o círculo de Gide é constantemente convocado nas páginas da revista coimbrã, o inverso não se verifica, pois a verdade é que não se detectam na NRF quaisquer referências à presença, embora um dos seus principais colaboradores tivesse já estanciado em Portugal e conhecesse a publicação de Régio. Com efeito, sabemos que Valery Larbaud permaneceu em Portugal de 26 de Janeiro a 7 Março de 1926. No primeiro mês, o escritor ficou hospedado na capital portuguesa e, a 26 de Fevereiro, parte à descoberta da província, instalando-se no Buçaco. Cativado pelos encantos de Lisboa e pela sedutora eufonia da língua portuguesa, o escritor francês aventura-se na sua aprendizagem. Esta breve estadia em terras lusas constitui a matéria do seu Caderno (Paris, edições Au Sans Pareil, 1926), posteriormente intitulado Jaune Bleu Blanc (Paris, edições La Nouvelle Revue Française, 1927), composto por três narrativas que darão a conhecer ao leitor francês uma pequena, mas significativa, parcela da língua e cultura portuguesas: "Lettre de Lisbonne" (evocação da capital portuguesa e da elite literária que o recebeu - colaboradores da revista Contemporânea, José Osório de Oliveira, João de Castro Osório, António Ferro, António Sérgio, etc.); “Écrit dans une cabine du Sud-Express" (análise de A Capital, de Eça de Queirós); “Divertissement Philologique” (uma autêntica sondagem filológica da língua portuguesa).

Este último texto, no qual intentava descrever "o sugestivo sabor da língua portuguesa" (HOURCADE, 1978, p. 7), será, durante largos anos, a única referência a Portugal presente nas páginas da NRF. Graças a Larbaud, o círculo da NRF ficou a saber que:

Où le vocabulaire portugais excelle en beauté et sonorité, peutêtre sur toutes les langues, c'est dans les noms d'objets de luxe et des matières précieuses. (...) A vrai dire, on attendait pas moins du langage des navigateurs, des rois importateurs de richesses de l'Afrique et de l'Amérique et du luxe de l'Asie, de ces princes qui passaient dans les rues de Lisbonne précédés d'éléphants, accompagnés d'esclaves porteurs d'éventails de plumes précieuses, et suivis de cages où étaient enfermés les animaux qui symbolisaient les diverses provinces de leur Empire (...). Oui, il y a quelque chose de fastueux, de manuélin dans la langue portugaise (...). A tel point que le mot portugais pour reine, malgré son indiscutable structure romane, a dans son orthographe quelque chose d'exotique, et comme un parfum d'Asie ou d'Insulinde dans ses vêtements : Rainha. LARBAUD, 1958, p. 941-942)

No que diz respeito à geração da presença, parece indesmentível que Larbaud conhecia não só a revista coimbrã, como também as obras dos seus principais mentores. Com efeito, sabemos que o escritor francês recebia a revista presença, que 
lhe era enviada pelos próprios directores. Numa carta a João Gaspar Simões, datada de Agosto de 1928, Régio pergunta-lhe se "a colecção para o Valery-Larbaud sempre partiu, devidamente acondicionada" (SIMÕES, 1977, p. 217). Por outro lado, constam da Bibliothèque luso-brésilienne de Valery Larbaud inúmeras obras de colaboradores da presença (Adolfo Casais Monteiro, Branquinho da Fonseca, José Régio, Adolfo Rocha, Alberto de Serpa, Vitorino Nemésio), algumas delas com dedicatórias dignas de interesse para o que nos ocupa. Um dos livros que Casais Monteiro envia a Larbaud é Sempre e sem fim. Poemas (1936), dedicado a "A Valery Larbaud, que um dia, num breve olhar, via mais da nossa literatura de que muitos 'especialistas' em longo convívio, ao espírito curioso de tudo o que ele vive, e ao grande artista" (apud MARTINS, 2007, Anexo III, p. 3). De Régio, Larbaud possui, na sua biblioteca, o Jogo de cabra cega (1934) e Biografia (1930), dedicada a "Valery Larbaud, esta Homenagem dum português" (ibid., p. 11). Em 1929, Branquinho da Fonseca oferece "a Valery Larbaud, com profunda admiração" (ibid., p. 6) a sua Posição de guerra - Drama em um acto.

No entanto, o contato amistoso de Valery Larbaud com a obra dos presencistas não parece ter sido pretexto suficiente para que a presença compareça nas páginas da NRF. Talvez o autor de Barnabooth fosse da opinião de Paulhan, que se recusou a publicar alguns poemas de Fernando Pessoa, afirmando, relativamente ao poeta português, que "ce n'est pas un poète selon mon coeur" (apud RIVAS, 2005, p. 36). A iniciativa havia partido de Pierre Hourcade, que terá entregue ao seu amigo Jules Supervielle alguns poemas traduzidos de Fernando Pessoa, destinados à publicação na Nouvelle Revue Française. Pessoa toma conhecimento deste projeto, através da sua correspondência com João Gaspar Simões que, numa carta datada do dia 2 de Março de 1931, o informava de que Hourcade acabava de "ter a satisfação de ver serem entregues à Nouvelle Revue Française as suas poesias traduzidas" (MARTINES, 1998 , p. 151) e que provavelmente seriam publicadas. Na carta seguinte, Simões regressa ao assunto, felicitando o poeta pela notoriedade de que então começava a usufruir:

Tinha recebido uma carta do Hourcade no dia em que recebi a sua. Nela me dizia que os seus poemas - ou as traduções deles - tinham sido recebidas pelo grande poeta francês Jules Supervielle com um grande entusiasmo e por êle levados à Nouvelle Revue Française, onde recebeu a promessa da sua publicação. Pela minha parte felicito-o da justíssima, embora tardia, homenagem que se começa a fazer à sua obra singular. E espero muito mais! (ibid., p. 155)

Os poemas de Fernando Pessoa não chegaram a aparecer na revista de Paulhan. No entanto, sabemos, graças à correspondência inédita que João Gaspar Simões manteve com alguns escritores franceses, entre os quais se encontram vários colaboradores da NRF (Jean Cassou, Hirsch, Jean Girodon, Charles Oulmont, Jules 
Supervielle), que nem todos partilhavam a opinião demeritória de Paulhan relativamente ao poeta português. Numa carta ao presencista, datada de 1929 e que a seguir transcrevemos, Jean Cassou, um dos colaboradores mais assíduos da NRF a partir de 1924, manifesta um grande interesse pela obra crítica de Simões, tendo sido ela a despertar-lhe a curiosidade pela literatura da sua geração, assim como uma crescente vontade de ler Fernando Pessoa e de receber a revista presença. O escritor da NRF confidencia ainda, com evidente pudor, a sua ignorância em matéria de literatura portuguesa, celebrando, contudo, a inigualável beleza da língua portuguesa:

Cher confrère, je vous remercie de l'envoi de vos Temas que j'ai lus avec beaucoup d'intérêt. D'ailleurs, j'avais déjà eu connaissance, par la Gaceta Literaria, de votre étude très aigüe sur les interprétations contradictoires d'Ortega et de Benda à propos de la plus ou moins grande déshumanisation de l'art actuel. Cela máa beaucoup arrangé et intéressé.

Je ne sais du portugais qu'une chose : c'est que c'est la plus belle langue du monde. Dites à vos aînés que je ne souhaite rien tant que de lire leurs livres. Mon ignorance en cette matière me fait honte.

Vous máavez donné envie de lire Pessoa et de recevoir la revue presença. Est-il possible de satisfaire ce dernier vœu?

Croyez, je vous prie, mon cher confrère, à ma cordiale sympathie. (CASSOU, 1929)

Contudo, foi preciso esperar mais de cinquenta anos, após o desaparecimento da presença, para que a NRF finalmente descobrisse a literatura portuguesa. Só em 1996 é que a prestigiada publicação dedicou um número especial à literatura portuguesa, preparando, para os seus leitores, uma pequena antologia intitulada "Ouvertures Portugaises" (NRF, $\mathrm{n}^{\circ}$ 522-523, Julho / Agosto de 1996, pp. 39-124) que coligia textos de José Cardoso Pires, Vergílio Ferreira, António Lobo Antunes, Agustina Bessa Luís, Maria Gabriela Llansol, Maria Velho da Costa, José Saramago e Luísa Costa Gomes.

\begin{abstract}
:
The fascination that French culture and literature have always exerted upon the Portuguese imaginary has been widely demonstrated. The writers who have gathered in 1927 around the literary review presença (1927-1940) bear witness to this Francophile seduction which they clearly admitted. In fact, browsing through the pages of the Coimbra review we find recurrent references
\end{abstract}


to both French language and culture. It should however be pointed out that the type of Francophilia found in presença presents singular and, to a certain extent, selective features, since, among the wide literary and cultural French repertoire, the presença generation chose as aesthetic and literary paradigm the Nouvelle Revue Française, published under the critical and doctrinal aegis of André Gide. However, the fascination and admiration that Régio's group devoted for the bande à Gide was far from reciprocal, and the dialogue between the two literary reviews/generations has remained one-sided, even if the presencistas made several attempts to foster a partnership with the intellectuals from the Nouvelle Revue Française.

Keywords: Nouvelle Revue Française, presença, Francophile influence, mediation, Luso-French dialogue.

\section{REFERÊNCIAS}

CASSOU, J. Carta a João Gaspar Simões (nov. 1929). Espólio João Gaspar Simões. Biblioteca Nacional, E 16, Caixa 05. CERISIER, A. Une histoire de la NRF. Paris : Gallimard, 2009.

FIUMI, L. Panorama da poesia italiana de hoje, presença, Coimbra, v. 2, n. 44, p. 6-7, abr. 1935.

HEBEY, P. L'esprit NRF 1908-1940. Paris : Gallimard, 1990.

HIRSCH, C.-H. Carta a João Gaspar Simões (fev. 1927). Espólio João Gaspar Simões. Biblioteca Nacional, E 16, Caixa 10.

HOURCADE, P. Defesa e ilustração da poesia portuguesa viva, presença, Coimbra, v. 2, n. 30, p. 13-15, jan./fev. 1931.

O ensaio e a crítica na presença. Colóquio/Letras, Lisboa, no38, p. 20-28, jul. 1977.

Temas de Literatura Portuguesa. Lisboa: Moraes Editores, 1978.

LARBAUD, V. Jaune bleu blanc. CEuvres. Paris : Gallimard, 1958.

LISBOA, E. André Gide: uma dívida de gratidão. Crónica dos anos da peste. Lisboa: Imprensa Nacional - Casa da Moeda, 1996, p. 82-97. . O segundo modernismo em Portugal. Lisboa: Biblioteca Breve, Instituto de Cultura e Língua Portuguesa, 1984. Poesia Portuguesa: do Orpheu ao Neo-Realismo. Lisboa: Biblioteca Breve, Instituto de Cultura e Língua Portuguesa, 1980. MARTINES, E. Cartas entre Fernando Pessoa e os directores da presença. Lisboa: Imprensa Nacional - Casa da Moeda, 1998. 
MARTINS, O. P. Valery Larbaud et le Portugal: lusophilie et médiation. Lição de Síntese apresentada para provas de Agregação no Grupo/ Sub-Grupo 1 - Cultura Francesa. Universidade de Aveiro, 2007. MONTEIRO, A. C. Sobre Eça de Queirós. presença, Coimbra, v. 1, n. 17, p. 1; 11, dez. 1928.

. O que foi e o que não foi o movimento da presença. Lisboa: Imprensa Nacional-Casa da Moeda, 1995.

MOURÃO-FERREIRA, D. presença da 'presença'. Porto: Brasília Editora, 1977.

. Reflexos da literatura francesa em Portugal (1920-1940). Actes du Colloque L'enseignement et l'expansion de la Littérature Française au Portugal. Paris : Fondation Calouste Gulbenkian, Centre Culturel Portugais, 1984, p. 133-141.

NOURISSIER, F. Un siècle NRF. Paris : Gallimard, 2000.

ORMESSON, J. d'. La N.R.F. : Le démon de la littérature. Une autre histoire de la littérature française. Paris : Nil Editions, 1997, p. 321-329. PIMENTEL, F.J. presença: labor e destino de uma geração. Braga: Angelus Novus Editora, 2002.

presença, edição facsimilada, Tomo I, II, III, Lisboa, Contexto Editora, 1993.

REDACÇÃO. A Gaceta Portuguesa de La Gaceta Literária. presença, Coimbra, v. 1, n. 18, p. 11, jan. 1929.

RÉGIO, J. A Folha da Parra, elementos para um romance, Tomaz Ribeiro Colaço. presença, Coimbra, v. 1, n. 33, p. 12-13, jul./out. 1931. RIVAS, P. Lusophiles français à Lisbonne en des temps incertains. Lisbonne - Atelier du Lusitanisme Français. Paris : Presses Sorbonne Nouvelle, 2005, p. 33-42.

SENA, J. de. Régio, Casais, A "presença" e outros afins. Porto: Brasília Editora, 1977.

SIMÕES, J. G. José Régio e a História do Movimento da 'presença'. Porto: Brasília Editora, 1977.

. Presença da literatura francesa na presença da literatura portuguesa. Actes du Colloque L'enseignement et l'expansion de la Littérature Française au Portugal. Paris: Fondation Calouste Gulbenkian, Centre Culturel Portugais, 1984, p. 123-132. 